\title{
Failure Modes Of Cold Formed Steel Angle Sections
}

\author{
Dr.A.Paulmakesh ${ }^{\mathrm{a}}$ Gizachew Markos Makebo $^{\mathrm{b}}$ \\ ${ }^{a}$ Associate professor, department of civil Engineering, Wolaita Sodo University, Ethiopia. \\ E-mail: paulmakesh1986@gmail.com \\ ${ }^{\mathrm{b}}$ Head, department of civil Engineering, Wolaita Sodo University, Ethiopia, \\ E- mail: gizemark2009@gmail.com
}

\begin{abstract}
Tension members consisting of single and double angles, single channels and similar sections are frequently used for lateral bracing and as truss elements. Such members normally have eccentric connections which results in bending of tension member. It is often permitted, by current design specifications, to neglect this eccentricity in the design of the member. The present study is focus on mode of failure on cold formed steel angle. This analysis carries single angles and double angles sections of $2 \mathrm{~mm}$ under plain (without Lipped) and with Lipped conditions subjected to tension. Analyses were carried out for thirty-six numbers of angle sections under condition such as double angle were connected same side to gusset plate and connected to opposite side. Figure shows connection failure and mode of failure. Local buckling, global buckling, tearing failure, net section failure, and block shear failure.
\end{abstract}

Keyword-Mode of failure, connection failure, cold formed steel, Net section Efficiency, Ultimate strength

\section{INTRODUCTION}

The design of commercial building is ruled primarily by useful necessities and therefore the want for economy of construction. In cross-sections, these buildings can vary from single or multi bay structures of larger span. Once supposed to be used as warehouses or craft hangers to smaller span buildings for factories, assembly plants, maintenance facilities, packing plants etc. The most dimensions can nearly invariably be settled by the actual operational activities concerned, however the structural designer's input on optimum spans and therefore the choice of appropriate cross-sections profile will have a crucial pertaining to achieving overall economy. Cold formed steel members are used in structures subjected to light and moderate loads. For such structures the use of hot rolled shapes is often uneconomical because the stresses developed are low, the smallest available sections are more than sufficient. Angles are the most common shape found in almost any structure due to their simplicity and ease of fabrication and erection. An aspect, which plays an important role in structural design, is the length of the building, i.e. the bay length. A balance between larger bays with fewer, heavier main elements such as columns, trusses, purlins, crane beams etc. It should be striked often or smaller bays with a large number of these elements with lower unit mass will yield a lesser foundation weight, there by ending in lower foundation prices. Cold Formed Steel (CFS) sheets offer a variety of outstanding properties including easy formability and smooth, clean surface are used in many applications.

\section{COLD FORMED STEEL}

It increases the design flexibility and allows very attractive, economical, and sustainable solutions. The factor of safety for angles under tension in the limit state format giving due considerations to blocks bearing failure and yielding of gross section was obtained. The knowledge and understanding of the behavior of cold formed steel bolted connections, to determine tensile capacity, bearing capacity and the interaction of tension and bearing capacities were performed. Thin sheet steel products are widely used in the construction industry, ranging from purlins to roofing and floor decking. These are normally 
accessible to the location as essential building components or as pre-assembled frames or panels. Their manufacturing process involves the formation of cold steel sections (without heat application) from uniform thick steel sheets. They are also sometimes called Light gauge steel sections. The thickness of the steel sheet used in the cold structure is usually 1 to $3 \mathrm{~mm}$. Significantly, thicker material up to $8 \mathrm{~mm}$ can be shaped if pre-galvanized material for special cases is required. The manufacturing method is important because it differentiates these products from hot rolled steel parts. Typically, the yield strength steel sheets utilized in cold formed sections is not less than $280 \mathrm{~N} / \mathrm{mm}^{2}$, higher quality steels have a tendency to be utilized, once in a while as low as $230 \mathrm{~N} / \mathrm{mm}^{2}$. Prefabricated cold formed steel assemblies embrace roof trusses, panelized walls or floors, and alternative prefabricated structural assemblies.

In order to understand the behavior of cold formed steel bolted connection tests, to determine tensile capacity, bearing capacity and the interaction of tension and bearing capacities were performed. Instead of failure through material yielding, compressed components tend to lose their stability. In the local buckling mode, flat plate fields cause displacements perpendicular to plane components and stress distribution. The shape of the section is slightly distorted during this mode as a result of only rotations of the plane part junctures are concerned. In the actual distorting buckling mode, displacement of cross section parts is mainly due to buckling e.g. flange stiffeners. The stiffness of the cross section could also be modified in each buckling modes, however the member most likely still has some post buckling capability. Since, the interpretation and or rotation of the complete cross section isn't concerned. In the global buckling mode, all cross section displacements are large, resulting in an overall loss of member stability. Global buckling modes depend mainly on cross section shape. Flexural buckling is typically common for cold formed members in the direction of minimum flexural stiffness.

\section{NET SECTION EFFICIENCY}

The net section efficiency ' $U$ ' of the member was calculated based on the ultimate load and the measured ultimate strength of material in tension coupon test (fu).

$\mathrm{U}=\mathrm{P}_{\exp } / \mathrm{P}_{\text {net }}, \quad \mathrm{P}_{\text {net }}=\mathrm{f}_{\mathrm{u}} * \mathrm{~A}_{\mathrm{n}}$, where

$\mathrm{U}=$ Net section efficiency

$\mathrm{f}_{\mathrm{u}}=$ Ultimate strength of the material

$\mathrm{A}_{\mathrm{n}}=$ Net area of the cross section

The experimental research results are presented and discussed. Tests conducted in cold formed steel angles are presented, connected by bolts, and submitted to tensile loads. When the bolted connection is considered, the angle does not deform evenly, showing the phenomenon known as shear lags. The steel angle collapse of the net section is examined for the calculation of the ultimate capacity of the tension members and the shear lag phenomenon is considered by the $\mathrm{U}$ factor. This coefficient reduces the net section and reduces the resistant capacity of the tensioned steel angle.

The tension member's efficiency is defined as the ratio of the members, design tensile capacity to normal or available tensile strength. Depending on the member section configuration and the type of end connection, the efficiency ranged from 0.70 to 1.10 . In the case of single unequal angles with a lip connected to the gusset plate by bolted connection, the highest efficiency valve is obtained and the lower valve is generally obtained in the bolted single equal angels.

To increase the efficiency of the outstanding angle in single angles and to reduce the length of the end connections, a short length of an angle section was sometimes used in the joint to connect the outstanding leg of the angle sections to the gusset plate. These angles are called Lug angles. Cold steel structural members can lead to more economic design than hot rolled members due to their high weight ratio, easily manufactured and built. Moreover, the significant advantages of cold-formed sections are increased yield strength, post-buckling strength and suitable for a wide range of applications. These 


\begin{tabular}{|c|c|c|c|c|c|c|}
\hline S.No & Description & Size & $\mathbf{P}_{\text {exp }}$ & $\mathbf{P}_{\text {net }}$ & $\mathbf{U}$ & Mode of failure \\
\hline \multirow[t]{3}{*}{1} & \multirow{3}{*}{$\begin{array}{l}\text { Equal size } \\
\text { Single angle } \\
\text { without Lip }\end{array}$} & $50 \times 50 \times 2$ & 34.58 & 43.34 & 0.80 & Global bending \\
\hline & & $60 \times 60 \times 2$ & 38.13 & 53.42 & 0.71 & Local buckling \\
\hline & & $70 \times 70 \times 2$ & 45.26 & 63.50 & 0.71 & Global bending \\
\hline \multirow[t]{3}{*}{2} & \multirow{3}{*}{$\begin{array}{l}\text { Single angle } \\
\text { with Lip }\end{array}$} & $50 \times 50 \times 10 \times 2$ & 41.25 & 52.42 & 0.79 & Block Shear \\
\hline & & $60 \times 60 \times 10 \times 2$ & 51.47 & 62.50 & 0.82 & Local buckling \\
\hline & & $70 \times 70 \times 10 \times 2$ & 62.47 & 72.58 & 0.86 & Net Section \\
\hline \multirow[t]{3}{*}{3} & \multirow{3}{*}{$\begin{array}{l}\text { Double angle } \\
\text { opposite side } \\
\text { without Lip }\end{array}$} & $50 \times 50 \times 2$ & 75.48 & 86.69 & 0.87 & Net Section \\
\hline & & $60 \times 60 \times 2$ & 87.29 & 106.85 & 0.82 & Local buckling \\
\hline & & $70 \times 70 \times 2$ & 108.17 & 127.01 & 0.85 & Net Section \\
\hline \multirow[t]{3}{*}{4} & \multirow{3}{*}{$\begin{array}{c}\text { Double angle } \\
\text { same side } \\
\text { without Lip }\end{array}$} & $50 \times 50 \times 2$ & 80.47 & 86.69 & 0.93 & Block Shear \\
\hline & & $60 \times 60 \times 2$ & 92.58 & 106.85 & 0.87 & Global bending \\
\hline & & $70 \times 70 \times 2$ & 112.28 & 127.01 & 0.88 & Block Shear \\
\hline \multirow[t]{3}{*}{5} & \multirow{3}{*}{$\begin{array}{l}\text { Double angle } \\
\text { opposite side } \\
\text { with Lip }\end{array}$} & $50 \times 50 \times 10 \times 2$ & 86.27 & 104.83 & 0.82 & Local buckling \\
\hline & & $60 \times 60 \times 10 \times 2$ & 92.47 & 124.99 & 0.74 & Local buckling \\
\hline & & $70 \times 70 \times 10 \times 2$ & 117.23 & 145.15 & 0.81 & Block Shear \\
\hline \multirow[t]{3}{*}{6} & \multirow{3}{*}{$\begin{array}{c}\text { Double angle } \\
\text { same side } \\
\text { with Lip }\end{array}$} & $50 \times 50 \times 10 \times 2$ & 87.46 & 104.83 & 0.83 & Net Section \\
\hline & & $60 \times 60 \times 10 \times 2$ & 98.75 & 124.99 & 0.79 & Block Shear \\
\hline & & $70 \times 70 \times 10 \times 2$ & 112.17 & 145.15 & 0.77 & Tearing failure \\
\hline \multirow[t]{3}{*}{7} & \multirow{3}{*}{$\begin{array}{c}\text { Unequal size } \\
\begin{array}{c}\text { Single angle } \\
\text { without Lip }\end{array}\end{array}$} & $50 \times 25 \times 2$ & 28.17 & 30.74 & 0.92 & Global bending \\
\hline & & $60 \times 30 \times 2$ & 32.78 & 38.30 & 0.86 & Block Shear \\
\hline & & $70 \times 35 \times 2$ & 37.85 & 45.86 & 0.83 & Net Section \\
\hline \multirow[t]{3}{*}{8} & \multirow{3}{*}{$\begin{array}{l}\text { Single angle } \\
\text { with Lip }\end{array}$} & $50 \times 25 \times 10 \times 2$ & 42.58 & 39.82 & 1.07 & Local buckling \\
\hline & & $60 \times 30 \times 10 \times 2$ & 48.75 & 47.38 & 1.03 & Local buckling \\
\hline & & $70 \times 35 \times 10 \times 2$ & 53.78 & 54.94 & 0.98 & Local buckling \\
\hline \multirow[t]{3}{*}{9} & \multirow{3}{*}{$\begin{array}{l}\text { Double angle } \\
\text { opposite side } \\
\text { without Lip }\end{array}$} & $50 \times 25 \times 2$ & 59.76 & 61.49 & 0.91 & Block Shear \\
\hline & & $60 \times 30 \times 2$ & 73.7 & 76.61 & 0.94 & Block Shear \\
\hline & & $70 \times 35 \times 2$ & 87.81 & 91.73 & 0.97 & Net Section \\
\hline \multirow[t]{3}{*}{10} & \multirow{3}{*}{$\begin{array}{l}\text { Double angle } \\
\text { same side } \\
\text { without Lip }\end{array}$} & $50 \times 25 \times 2$ & 58.81 & 61.49 & 0.96 & Block Shear \\
\hline & & $60 \times 30 \times 2$ & 62.78 & 76.61 & 0.82 & Tearing failure \\
\hline & & $70 \times 35 \times 2$ & 83.47 & 91.73 & 0.91 & Local buckling \\
\hline \multirow[t]{3}{*}{11} & \multirow{3}{*}{$\begin{array}{l}\text { Double angle } \\
\text { opposite side } \\
\text { with Lip }\end{array}$} & $50 \times 25 \times 10 \times 2$ & 72.37 & 79.63 & 0.97 & Block Shear \\
\hline & & $60 \times 30 \times 10 \times 2$ & 89.34 & 94.75 & 0.96 & Net Section \\
\hline & & $70 \times 35 \times 10 \times 2$ & 106.35 & 109.87 & 0.96 & Local buckling \\
\hline \multirow[t]{3}{*}{12} & \multirow{3}{*}{$\begin{array}{l}\text { Double angle } \\
\text { same side } \\
\text { with Lip }\end{array}$} & $50 \times 25 \times 10 \times 2$ & 71.58 & 79.63 & 0.90 & Local buckling \\
\hline & & $60 \times 30 \times 10 \times 2$ & 83.147 & 94.75 & 0.88 & Tearing failure \\
\hline & & $70 \times 35 \times 10 \times 2$ & 92.47 & 109.87 & 0.84 & Tearing failure \\
\hline
\end{tabular}

sections are primarily thin walled with moderate to terribly high flat widths or elements.

Table 1 Net section Efficiency of angle section thickness of $2 \mathbf{m m}$

\section{MODES OF FAILURE}

A tension member was loaded until strain hardening is reached and elongates excessively before the fracture causing the members to fail at the angle. The failure modes for single and double- angle specimens were observed during the test. Generally, different types of failure modes were used for single 
and double angle sections, namely global bending, local bending, local buckling, tearing failure, shear failure, net fracture. The failure mode depends on the cross- sectional area and the connection stiffness.

The initiation of a particular failure mode is observed to depend on the geometric characteristics, material properties, and loading conditions of the angle sections. The angle sections of the gusset plate remained straight during the loading process. The gusset plate of the angle sections was bent during tensile loading conditions in the case of single angles. The angle sections of the moulding plate remained straight during the loading process. The gusset plate of the angle sections was bent during tensile loading conditions in the case of single angles. This bending type is referred to as global bending. Fig 1 shows the global bending of specimens of single plain angle.

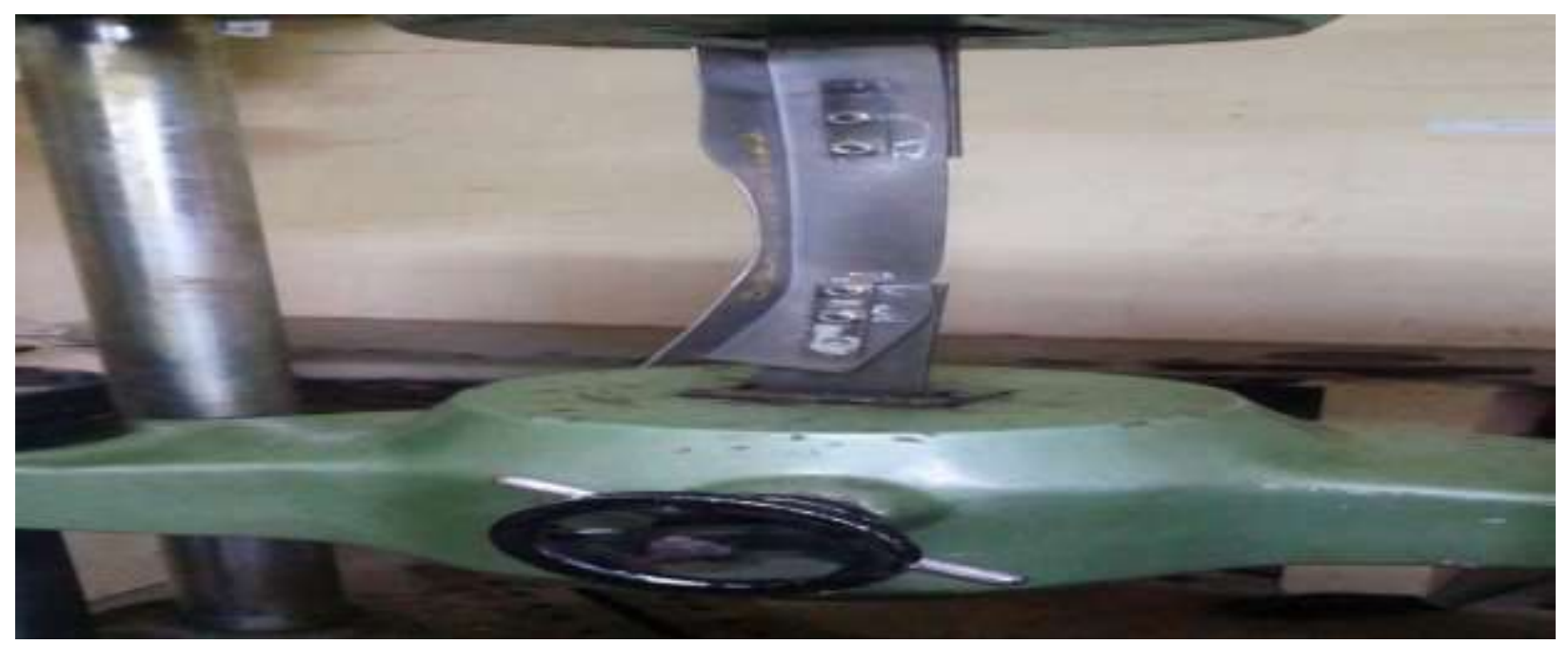

Fig 1 Failure due to global bending of single plain angle specimen

The load of tension was applied in the members, the corners of the angles gradually separated from the gusset plates at the two ends for both single and double angles. The gap between the corner of the connected leg and the gusset plate was then formed. This type of bending is referred to as local bending. Larger gaps typically have been linked to higher cross- sectional eccentricity, smaller angle thicknesses, and shorter connection lengths. Fig 2 to 3 show the local bending of the Lip specimen of single angles. The visible gap length was usually from the edge of the angle to the inner bolt. The width of gap from one specimen to another, the valve is $12 \mathrm{~mm}$ was observed in the angle sections.

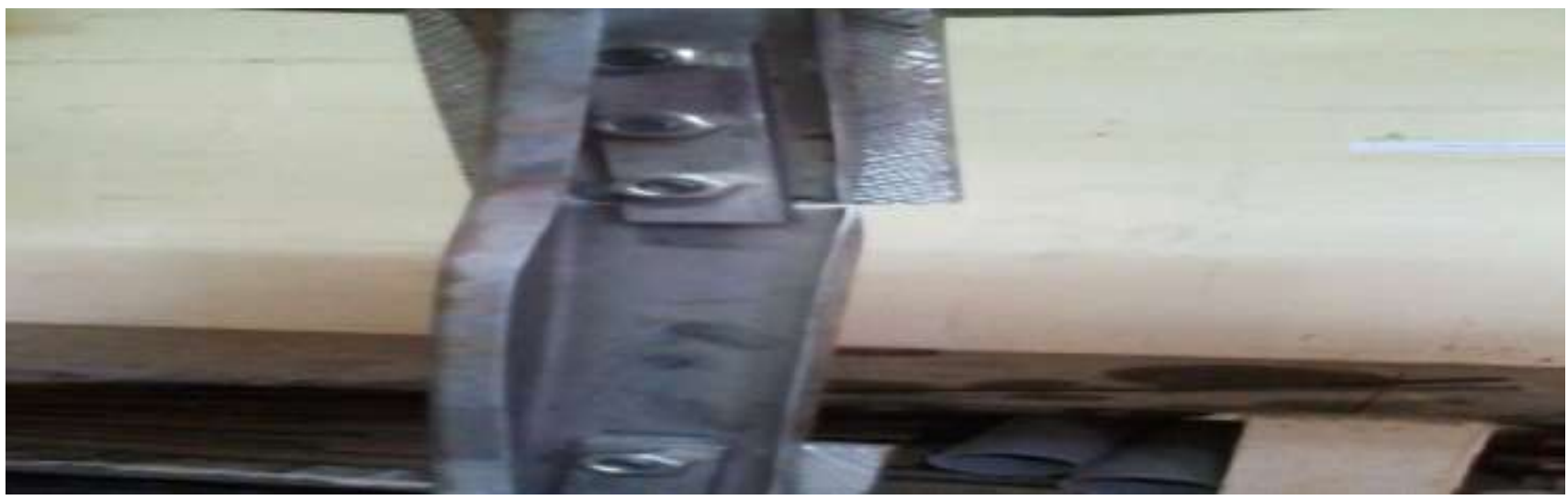

Fig 2 Failure due to local bending of single angle with Lip 


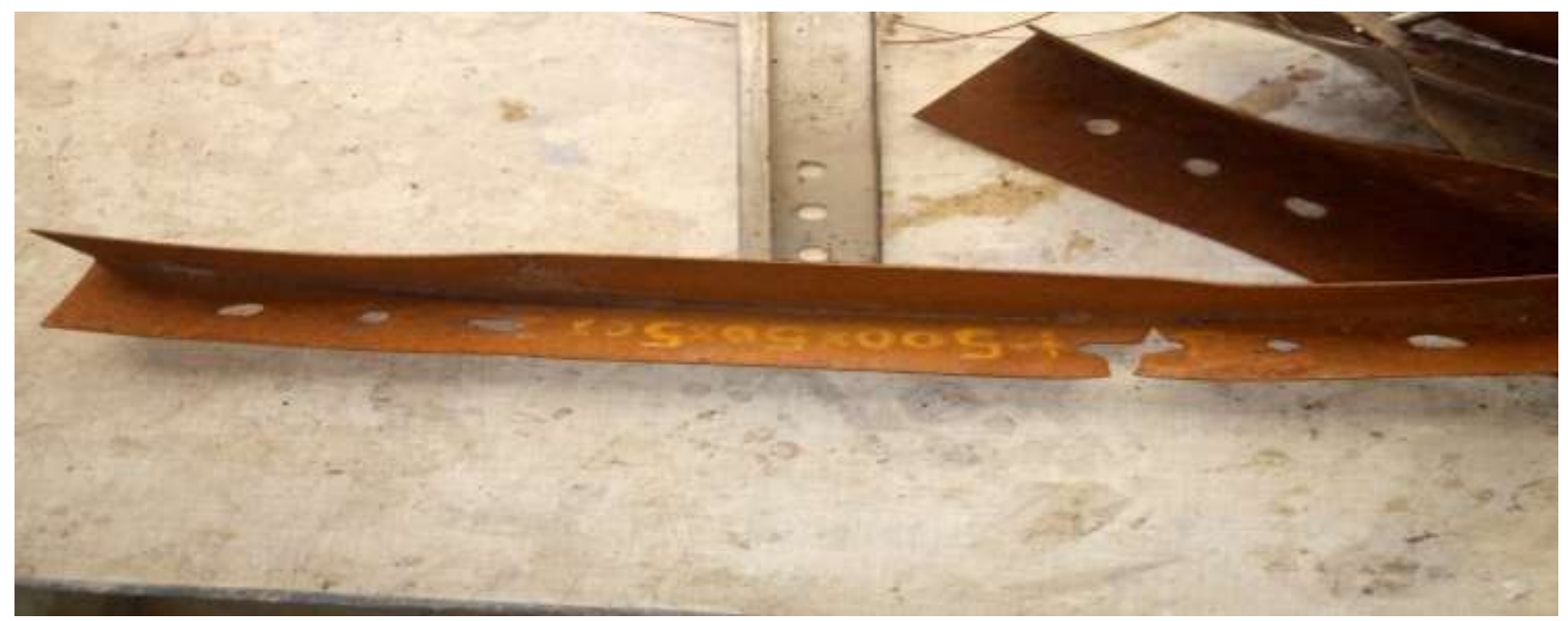

Fig 3 Failure due to local bending

In the case of single angles tested in the bolted connection, local buckling was observed. The local buckling occurred in the middle of the flange or between the mid height and one third of the angle section. The specimens carried a certain load beyond the ultimate load until failed. It was observed that all the bolts were still close after the tests were completed. During tests, the bolts were not highly stressed. The outstanding leg that is compressed experiences a local buckling closer to the supports. Fig 4 shows failures due to local buckling of single angle specimens.

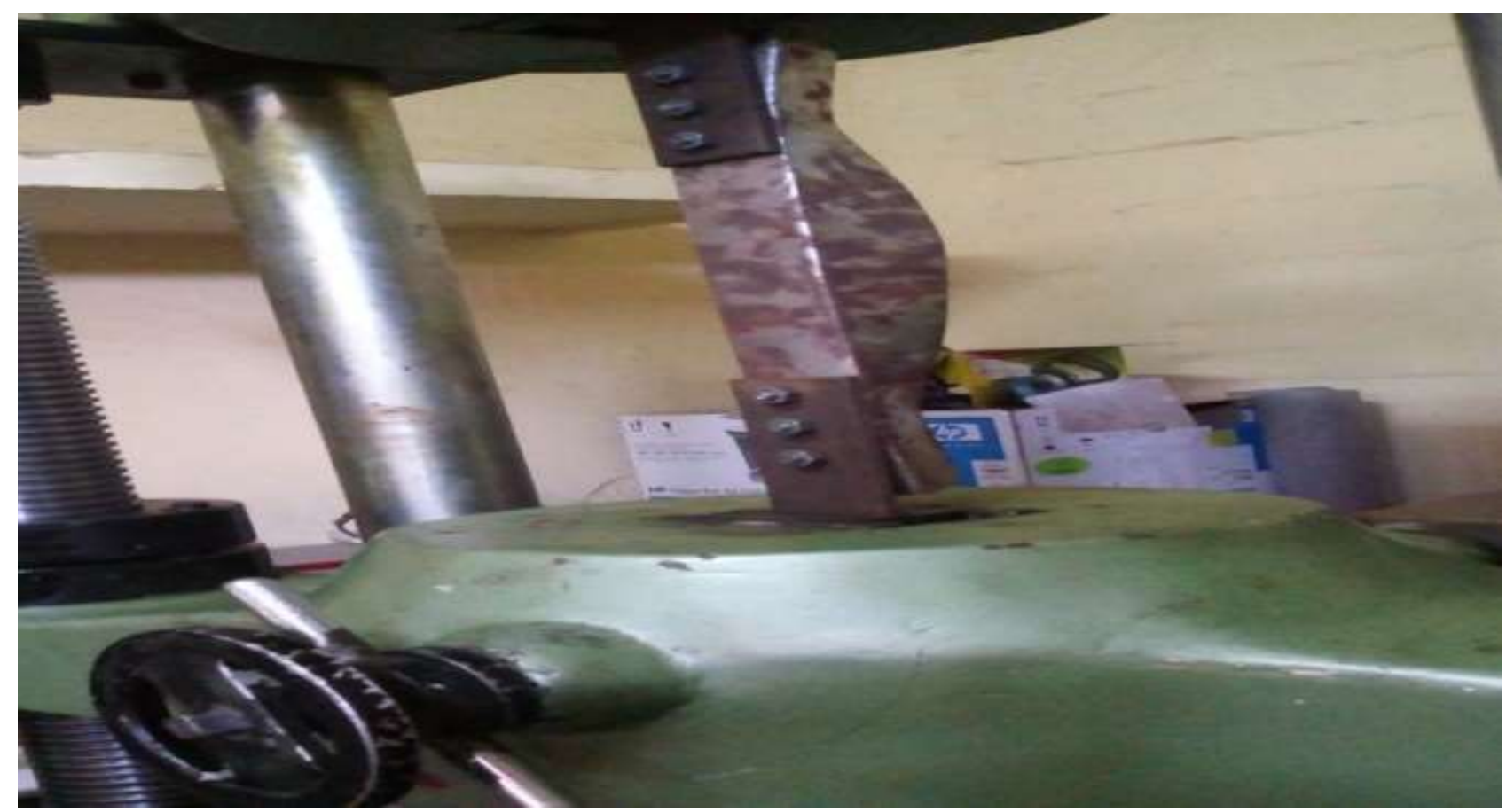

Fig 4 Failures due to local buckling of single angle specimen 70x70x2 


\section{CONNECTION FAILURE}

Connect failures are not so ductile as angle failures. There are three general failure categories that occurred during testing. Failure to tear, failure of the shear block and failure of the Net section.

\subsection{Tearing failure}

This type of failure occurred in most of the bolts inside as the ultimate load was achieved. The minimum edge distance in the angles is provided, and the yielding is initiated at the innermost bolthole. If the bolts are stronger than the plates, a tearing failure occurred. The tension failure of a bolt is shown in Fig.5

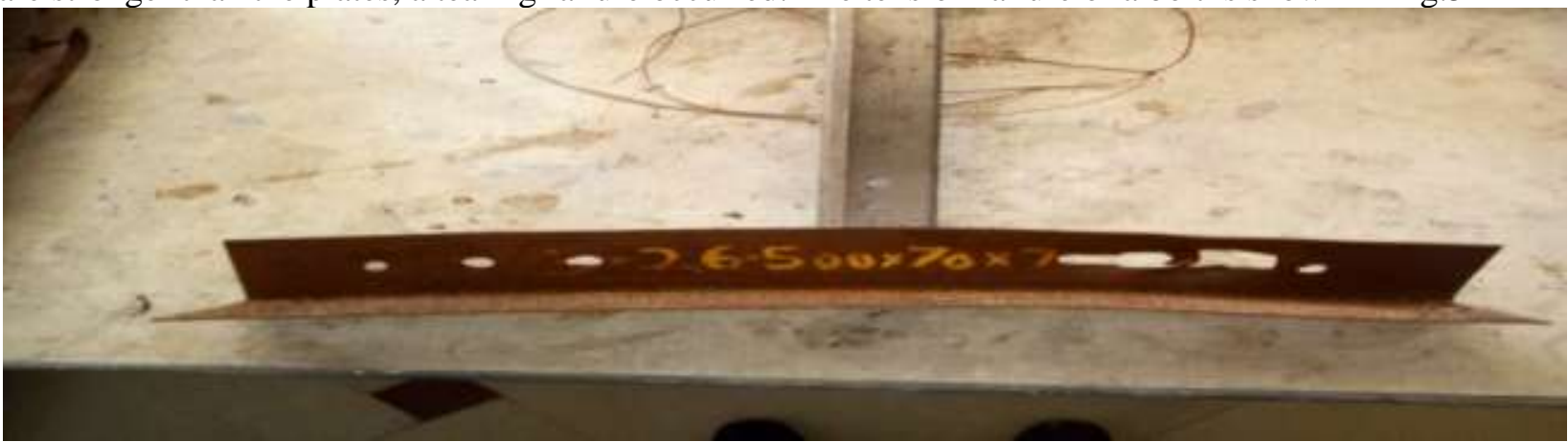

Fig 5 Failures due to tearing in bolts of single angle specimen 70x70x2

\subsection{Block shear failure}

This type of failure occurs at a faster rate compared to tearing failure. Segments of blocks of material at end of member shear out due to the possible use of high strength bolts resulting in smaller connection length. Yielding of two innermost boltholes, the net section area reduces considerably, which reduces in bock shear failure. Fig 7 to 10 shows the block shear failure of all angle specimens. Limit state of block shear are combined shear and tension failure.

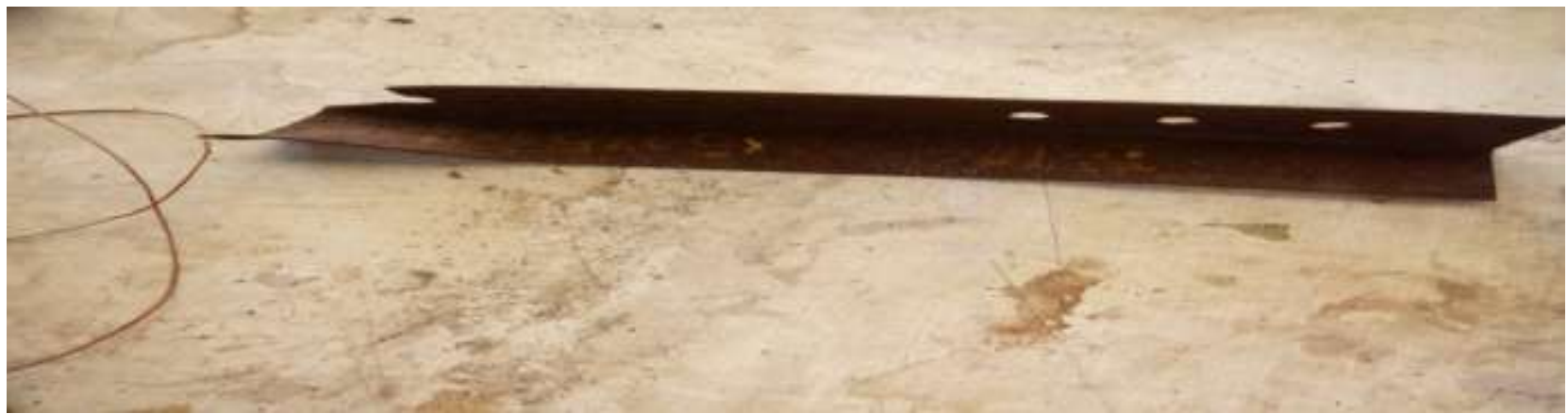

Fig 7 Failures due to block shear of single equal angle specimen 50x50x2

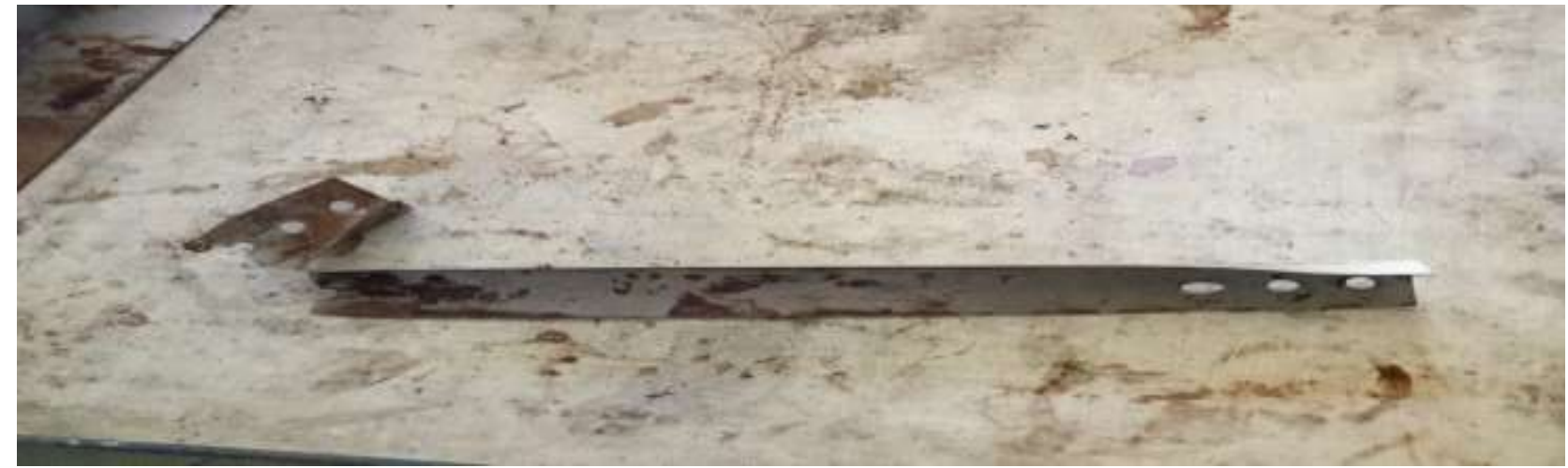

Fig 8 Failures due to block shear of single equal angle specimen 50x50x2 


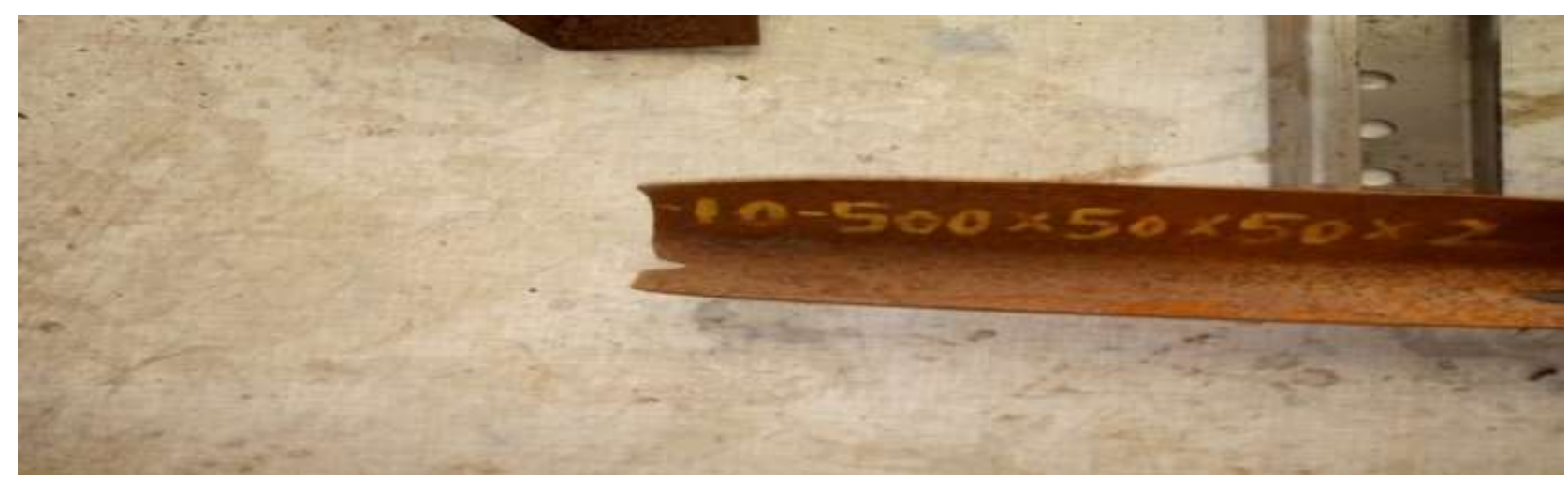

Fig 9 Failures due to block shear of single unequal angle specimen 50x50x2

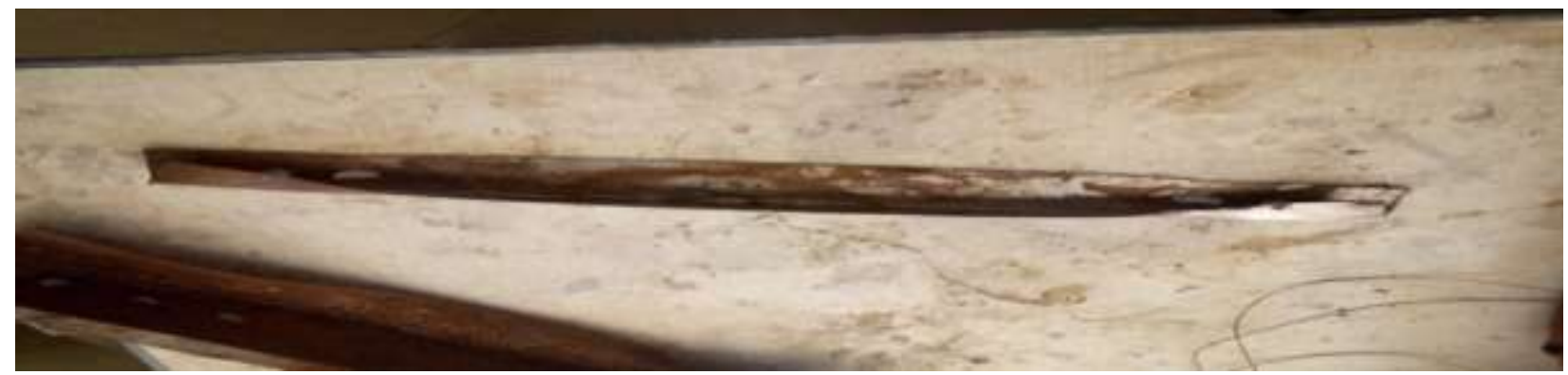

Fig 10 Failures due to block shear of single equal angle specimen with Lip 70x70x2

\subsection{Net section fracture failure}

Fig 11 to 12 shows the net section, failure of angle sections specimens. The rupture of the member when the net cross section of the member reaches the ultimate stress. If the material is ductile, local yielding at the edge of the hole due to stress concentration allows for a redistribution of stress in the net section. The failure occurs at the innermost bolt hole and the crack towards it.It is also observed that when the connected leg fails due to net section fracture, the outstanding leg under compressive stress suffers local buckling.

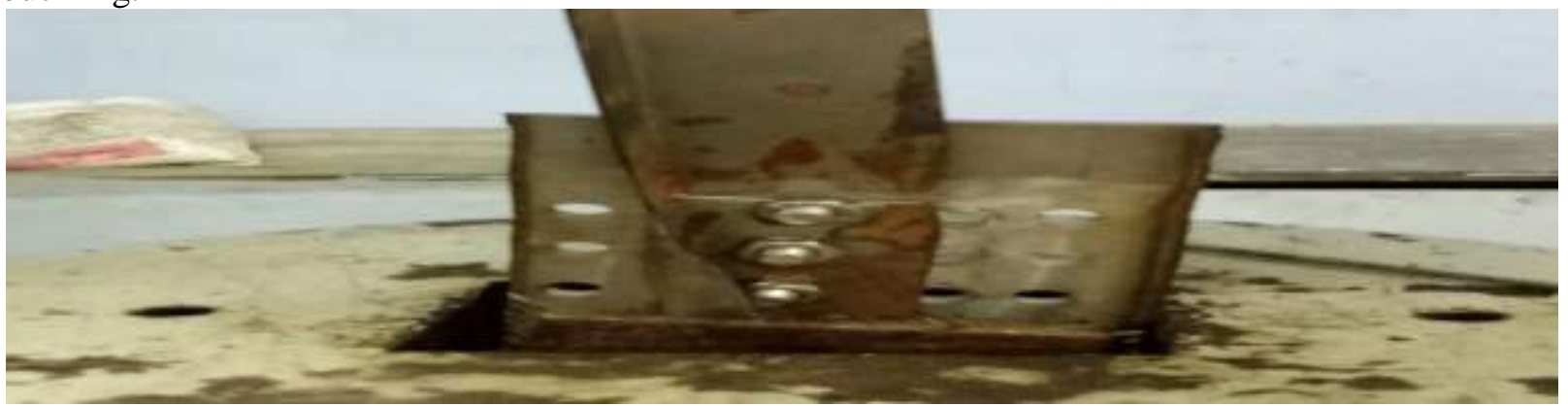

Fig 11 Failures due to net section of single un equal angle specimen $70 \times 35 \times 2$

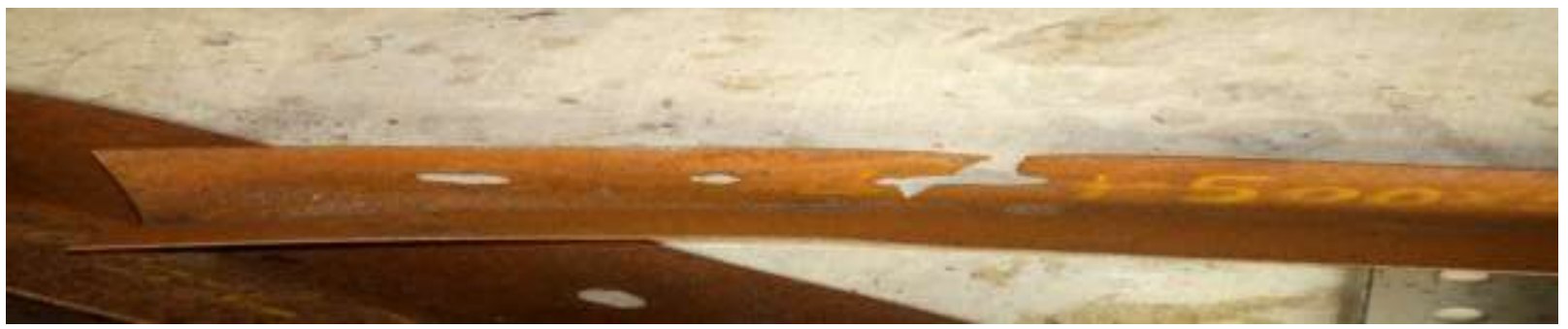

Fig 12 Failures due to net section of single angle specimen $50 \times 50 \times 2$ 


\section{FAILURE MODES OF BOLTED CONNECTIONS}

Failure of the connected part because of bearing exerted by the fastener (average bearing stress is $f_{p}=$ $\mathrm{P} / \mathrm{dt}$ ). If the hole is slightly larger than the fastener and the fastener is assumed to be placed loosely in the hole. Contact between the fastener and connected part will exist over approximately 50\% of the circumstances of the fastener. The edge distance and bolt spacing affect the bearing problem. Connections forms an important part in any structure and are designed more conservatively than members.

There are four types of failure mechanisms, which are shown in Fig 5.3. They are

- Longitudinal shearing of the sheets by the bolt

- Bearing failure with materials shearing and piling up in front of the bolt

- Transverse tension tearing of the sheet

- Shearing of Bolts taking place in threaded portion of the bolt

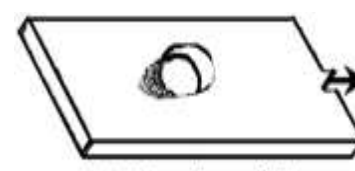

(a) Bearing failure

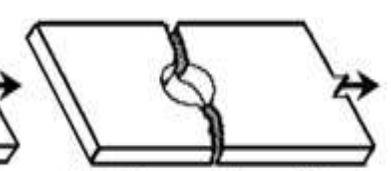

(b) Net-tension failure

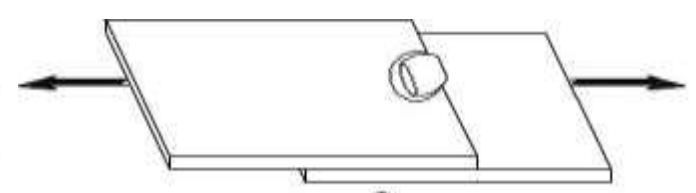

a

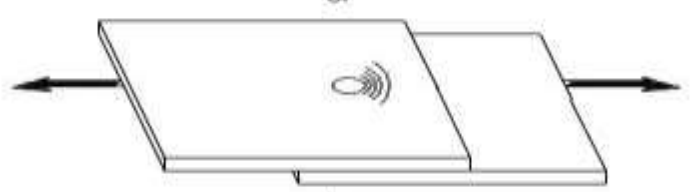

b

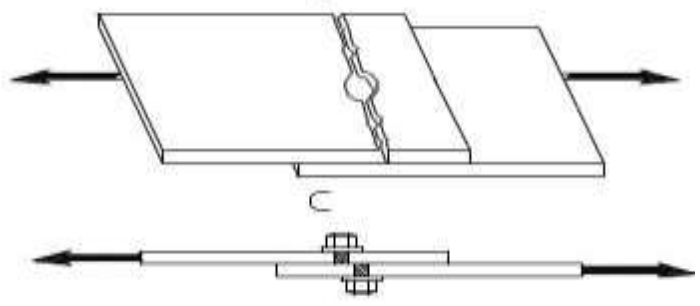

d

Fig 13 Failure modes in bolted connection

\subsection{Longitudinal shearing of the steel sheets}

When the edge distance ' $\mathrm{e}$ ' is relatively small, connections usually fail in longitudinal shearing of the sheet along two parallel lines. The displacement between the steel sheet and steel means that the failure of the angle section is longitudinal shear stress. The length and the thickness of the angle section tested provided this failure mode.

\subsection{Bearing or piling up of steel sheet}

If the edge distance ' $\mathrm{e}$ ' is large enough, the connection may fail by carrying or piling the sheet of steel in front of the bolt. The bearing strength of the bolted connections depends on several parameters, including the connected the tensile strength, the connected part's the thickness of the connected part, the type of joint, the $\mathrm{f}_{\mathrm{u}} / \mathrm{f}_{\mathrm{y}}$ ratio of the connected part, the use of washers and the rotation of fasteners.

\subsection{Tearing of sheet at net section}

The type of failure by tearing of sheets in the net section in bolted connections is related to stress concentrations caused by the presence of bolts and the concentrated localized force transmitted by the bolt to the sheets. 


\subsection{Shearing of bolt}

If the provided bolt area is insufficient to carry the applied load shearing of the bolt. This kind of failure is sudden and should therefore be avoided in every connection.

\subsection{Design criteria for bolted connections}

Design strength should be more than design load. Thecentre of gravity of bolts should coincide with the centre of gravity of the connected members. The length of connection should be kept as small as possible. It should satisfy requirements specified in clause 10.2 regarding spacing, such as

- Pitch shall not be less than $2.5 \mathrm{~d}$

- Minimum edge distance is $1.5 \mathrm{~d}_{\mathrm{o}}$

- Diameter of bolt hole $\left(\mathrm{d}_{\mathrm{o}}\right)$ is $\mathrm{d}+2 \mathrm{~mm}$

- Pitch of the Bolts (p) : It is the centre-to-centre spacing of the bolts in a row, measured along the direction of load.

- Gauge Distance (g) : It is the distance between the two consecutive bolts of adjacent rows and is measured at right angles to the direction of load.

- Edge Distance (e): It is the distance of bolt hole from the adjacent edge of the plate.

In the determination of the allowable load the following points should be consider such as minimum spacing and edge distance in line of stress, tensile capacity of steel sheets. Bearing capacity between bolts and steel sheets and shear capacity of bolts.

The clear distance between bolts which are arranged in rows parallel to the directions of force, also the distance from center of any bolt to that end or other boundary of the connecting member towards which the pressure of the bolt is directed shall not be less than $1.5 \mathrm{~d}$ nor less than

where

$$
\mathrm{P} /(0.6 \mathrm{fy})
$$

$\mathrm{d}=$ diameter of bolt

$\mathrm{P}=$ force transmitted to bolt

$\mathrm{f}_{\mathrm{y}}=$ yield point

The research basis for design criteria and the behavior and strength of bolted structural joints based on experimental and theoretical studies. Provides the basis for many provisions of the AISC Specification. The ductility is essential in various ways for the proper functioning of steel structures and is particularly important in the behavior of connections.

\subsection{Lug Angle}

Lug Angle is one such development, which can be used effectively in designing of tension member. Lug angle is small piece of angle used to connect outstand legs of the members to the gusset plate. The purpose of lug angle is to reduce the length of connection to the gusset plate and to reduce shear lag effect. If lug angle is used then the unconnected lengths of main angle behave like a connected leg and entire cross section area of the angle become effective in resisting tension. So if lug angle is used, then efficiency of the tension member increases because it reduces shear lag effect.

Sometimes the main angle carries a huge amount of load and to make corrections of this type of angle section with the main member to transfer the load. We need a large number of large number of bolt, so if we use a large number of bolt or large length of weld then the size of the gusset plate become very high and if size of the gusset plate become high material required for gusset plate will be large and it will be uneconomical. 


\section{CONCLUSION}

The study focused on mode of failure in cold formed angle section under tensile loading. Here the connection length is increased by increasing the pitch between the holes instead of increasing the number of bolts .In all of the specimens, failure is caused due to the partial net section rupture of the connected leg adjacent to the lead bolt hole. The analysis indicated an excellent agreement with the experimental failure capacities of the specimens with large connection eccentricities. In addition, these models are able to accurately capture the partial net section rupture failure mode observed in the experimental specimens. The factor 1.10, 1.15 and 1.08 were introduced in the proposed equation for the calculation of nominal tensile strength for yielding of gross section, net section failure and block shear failure.Economy are achieved by using the cold formed steel angle sections wherever possible in hot rolled steel structures. The advantages of cold formed steel lie in the ease of forming the variety of shapes designed to use the material effectively and to simplify and the speed up the construction operation.

\section{REFERENCES}

[1] AISC, "Load and resistance factor design specifications for structural steel building", 2nd ed. Chicago (IL), American Institute of Steel Construction, 1995.

[2] J. M. Gross, J. G. Orbison and R. D. Ziemian, "Block shear tests in high strength steel angles", AISC Engineering Journal, vol. 32 (3), pp. 117-122 (1995).

[3] H. I. Epstein and R. Chamarajanagar, "Finite Element studies for correlation with block shear tests", Comput Struct, vol. 61, pp. 967-974 (1996).

[4] G. L. Kulak and E. Y. Wu, "Shear lag in bolted angle tension members", ASCE Journal Struct Eng, vol. 123 (9), pp.1144-1152 (1997).

[5] J. G., Orbison, M. E Wagner and W. P. Fritz, "Tension plane behavior in single-Row bolted connections subject to block shear", Journal of Constructional Steel Research, vol. 49, pp. 2-15 (1999).

[6] K. E. Barth, J. G. Orbison and R. Nukala, "Behavior of steel tension members subjected to uniaxial loading", Journal of Constructional Steel Research, vol. 58, pp. 1103-1120 (2002).

[7] James, BP \& Nethercot, DA 2003, 'Ultimate strength of bolted moment-connections between coldformed steel members', Thin-Walled Structures, vol. 41, no. 11, pp. 1019-1039

[8] James Orbison, G \& Karl, E 2002, 'Net Section in Tension Members with Connection Eccentricity', ASCE Journal of Structural Engineering, vol. 128, no. 8, pp. 976-985

[9] Krishnan, L \& Dineshraj, CS 2015, 'Experimental Investigation of Cold-Formed Steel Section Flexural Member with Triangular Web', IOSR Journal of Mechanical and Civil Engineering, vol. 12, no.

2, pp. 36-39

[10] Kulak, GL \& Grondin, GY 2001, 'AISC Rules for Block Shear in Bolted Connections', Engineering Journal, vol. 5, no. 4, pp. 199-203

[11] Kulkarni, RB \& Shweta, B 2014, 'Parametric study and comparison of Indian standard code with British standard code for the Design of Light gauge cold formed flexural members', International Journal of Engineering and Technical Research, vol. 2, no. 11, pp. 325-332 